\title{
DERECHOS SOCIALES DE PRESTACIÓN Y OBLIGACIONES POSITIVAS DEL ESTADO EN LA JURISPRUDENCIA DEL TRIBUNAL EUROPEO DE DERECHOS HUMANOS
}

ENCARNA CARMONA CUENCA 
SUMARIO

1. INTRODUCCIÓN. 2. LOS DERECHOS SOCIALES DE PRESTACIÓN Y SU PROBLEMÁTICA JUSTICIABILIDAD. 3. LAS OBLIGACIONES POSITIVAS DEL ESTADO EN LA JURISPRUDENCIA DEL TEDH. 4. LAS TÉCNICAS DE PROTECCIÓN DE LOS DERECHOS SOCIALES DE PRESTACIÓN EN LA JURISPRUDENCIA DEL TEDH. 4.1 Planteamiento general. 4.2 Aplicación de la prohibición de discriminación del artículo $14 \mathrm{CEDH}$ a determinadas prestaciones sociales. 4.3 Ampliación del contenido de varios derechos reconocidos en el Convenio. 5. EN ESPECIAL: LA PROTECCIÓN DE LOS DERECHOS SOCIALES DE PRESTACIÓN A TRAVÉS DE LA DOCTRINA DE LAS OBLIGACIONES POSITIVAS DEL ESTADO. 5.1 El derecho a la protección de la salud. 5.2 El derecho a la vivienda. 6. A MODO DE CONCLUSIÓN. 


\title{
DERECHOS SOCIALES DE PRESTACIÓN Y OBLIGACIONES POSITIVAS DEL ESTADO EN LA JURISPRUDENCIA DEL TRIBUNAL EUROPEO DE DERECHOS HUMANOS ${ }^{1}$
}

\author{
ENCARNA CARMONA CUENCA* \\ Profesora Titular de Derecho Constitucional \\ Universidad de Alcalá
}

\section{INTRODUCCIÓN}

Es conocida la diferente justiciabilidad de los derechos civiles y políticos y de los derechos económicos y sociales (en adelante, y para sintetizar, «derechos sociales») en las diversas instancias nacionales e internacionales de protección de los derechos. En especial: los derechos sociales de prestación (educación, protección de la salud, vivienda y protección social, entre otros) presentan muchas dificultades para su justiciabilidad. La principal razón que se arguye es la dificultad económica: los Estados precisarían tener una capacidad económica muy elevada para hacer efectivos esos derechos y los tribunales (nacionales e interna-

1 Terminé de redactar este artículo durante una estancia de investigación en el Max Planck Institute for Comparative Public Law and International Law de Heidelberg (Alemania), gracias a la concesión de una Ayuda para Estancias de movilidad de profesores e investigadores seniores en centros extranjeros de enseñanza superior e investigación, incluido en el Programa Salvador de Madariaga 2016.

* Facultad de Derecho. Universidad de Alcalá. C/ Libreros, 27, 28801 Alcalá de Henares (Madrid). Email: e.carmona@uah.es 
cionales) no deben sustituir a los parlamentos y gobiernos estatales en la definición de las políticas públicas.

En el seno del Tribunal Europeo de Derechos Humanos (TEDH), encargado de proteger los derechos reconocidos en el Convenio Europeo de Derechos Humanos, la regla es la inadmisión de demandas basadas en derechos sociales no reconocidos expresamente pero, a pesar de ello, se ha otorgado cierta eficacia a algunos de estos derechos a través de diversas técnicas, como ya se ha estudiado en varios trabajos. Una de estas técnicas ha sido la aplicación de la conocida doctrina de las obligaciones positivas del Estado.

En este trabajo trato de analizar cómo se ha aplicado esta doctrina a la protección de los derechos sociales de prestación y cuáles son sus posibilidades y límites. En primer lugar, intento acotar el tema, definiendo los derechos que son objeto de este trabajo y que son los que plantean las mayores dificultades de justiciabilidad: los derechos sociales de prestación.

En segundo lugar, hago referencia a la doctrina de las obligaciones positivas del Estado, tal y como la ha establecido el TEDH, quien la ha aplicado, en primer lugar y sobre todo, a los derechos civiles y políticos.

En tercer lugar, destaco algunas de las técnicas que ha utilizado el TEDH para otorgar cierta eficacia jurídica a los derechos sociales de prestación.

En cuarto lugar, me centro en la aplicación de la doctrina de las obligaciones positivas del Estado a la protección de los derechos sociales de prestación en la jurisprudencia del TEDH. Trato de extraer de la jurisprudencia del TEDH algunas definiciones de las obligaciones positivas del Estado para proteger los derechos sociales de prestación. Es posible apreciar cómo estas obligaciones están mucho menos definidas y concretizadas que las derivadas de los derechos civiles y políticos.

Por último, intento obtener alguna conclusión sobre cuáles son las posibilidades y límites de la aplicación de esta doctrina a la protección de los derechos sociales de prestación.

\section{LOS DERECHOS SOCIALES DE PRESTACIÓN Y SU PROBLEMÁTICA JUSTICIABILIDAD}

En los distintos ámbitos de protección de los derechos humanos (Naciones Unidas, Consejo de Europa, Sistema Interamericano, constituciones nacionales...) es una constante la diferente justiciabilidad de los derechos civiles y políticos y de los derechos sociales. Mientras que aquellos gozan de sistemas de 
garantía mucho más elaborados y judicializados, los derechos sociales son protegidos por sistemas más cercanos al soft law.

Es significativa la situación en el ámbito del Consejo de Europa. Allí se aprobaron dos Convenios distintos para la protección de ambas categorías de derechos: El Convenio Europeo para la Protección de los Derechos Humanos y de las Libertades Fundamentales, más conocido como Convenio Europeo de Derechos Humanos (CEDH), que fue adoptado por el Consejo de Europa en Roma el 4 de noviembre de 1950 y la Carta Social Europea (CSE), aprobada en Turín el 18 de octubre de 1961 y revisada en 1996. Mientras que el sistema del CEDH incluye un Tribunal, el Tribunal Europeo de Derechos Humanos, cuyas decisiones tienen fuerza vinculante para los Estados (art. $46 \mathrm{CEDH}$ ) y un procedimiento de demandas individuales, el órgano de control de la CSE es el Comité Europeo de Derechos Sociales (CEDS) y el sistema de protección se basa en la presentación de Informes por los Estados. Además, partir de 1998, para los Estados que han ratificado el Protocolo Adicional a la CSE de 1995, el sistema incluye la posibilidad de interponer reclamaciones colectivas. Como resultado de estas reclamaciones colectivas, el CEDS remitirá informes al Comité de Ministros, quien puede emitir recomendaciones a los Estados ${ }^{2}$.

Sin embargo, se ha puesto de manifiesto en la doctrina la necesaria indivisibilidad de los derechos bumanos $^{3}$, su imprescindible interconexión. Sin la garantía de, al menos, un mínimo nivel de derechos sociales, no es posible el disfrute de derechos como la libertad de pensamiento, la libertad de expresión o los derechos al honor, intimidad e inviolabilidad del domicilio, entre otros. Y, del mismo modo, no se pueden disfrutar plenamente los derechos sociales si no es en un contexto de garantía de la libertad.

2 Sobre la protección de los derechos sociales de prestación en los distintos órganos internacionales europeos, vid., JIMENA QuesadA, L. (2011), «La jurisprudencia europea sobre derechos sociales», en: Von Bogdandy, A.; Fix-Fierro, H.; Morales Antoniazzi, M. y Ferrer MacGregor, E., Construcción y papel de los derechos sociales fundamentales. Hacia un Ius Constitutionale Commune en América Latina, México: Instituto de Investigaciones Jurídicas/Max Planck Institut für ausländisches öffentliches Recht un Völkerrecht/Instituto Iberoamericano de Derecho Constitucional/ UNAM y ChatTon, G. T. (2008), «La armonización de las prácticas jurisprudenciales del Tribunal Europeo de Derechos Humanos y del Comité Europeo de Derechos Sociales», en Revista de Derecho Político, UNED, N. ${ }^{\circ}$ 73. Sobre la protección en los órganos internacionales: BINDER, C.; Hofbauer, S. A.; Piovesan, F.; Steiner, A. Z. and Steiner, E. (Eds.) (2016), Social Rights in the Case Law of Regional Human Rights Monitoring Institution, Antwerp, Vienna, Graz: Intersentia.

3 Vid., por ejemplo, Escobar Roca, G. (2012), «Indivisibilidad y derechos sociales. De la Declaración Universal a la Constitución», Lex Social. Revista de los Derechos Sociales N. ${ }^{\circ} 2$. 
Esta idea fue consagrada a nivel internacional en la famosa Declaración y Programa de Acción de Viena, aprobada por la Conferencia Mundial de Derechos Humanos de Naciones Unidas el 25 de junio de 1993, según la cual:

«Todos los derechos humanos son universales, indivisibles e interdependientes y están relacionados entre sí. La comunidad internacional debe tratar los derechos humanos en forma global y de manera justa y equitativa, en pie de igualdad y dándoles a todos el mismo peso» ${ }^{4}$.

Ahora bien, no todos los derechos sociales tienen la misma naturaleza. En las declaraciones de estos derechos se suelen incluir figuras diversas. Sintetizando, podemos distinguir dos grandes categorías de derechos sociales ${ }^{5}$ : a) Derechos sociales de libertad, de naturaleza similar a la mayoría de los derechos civiles y políticos reivindicados en las revoluciones liberales, es decir, se trata de derechos que exigen, fundamentalmente, una actitud negativa, de no injerencia, del Estado. De este tipo son los derechos de libre sindicación y de huelga y b) Derechos sociales de prestación ${ }^{6}$. Éstos otorgan al sujeto un título para exigir que se le entreguen ciertos bienes, se le presten ciertos servicios o se le transfieran ciertos recursos. Entre ellos, podemos encontrar supuestos en los que se trata de demandar la entrega de un bien (derecho a una vivienda digna), la prestación de un servicio (educación, protección de la salud...) o la percepción de una asignación económica (pensiones, subsidios...) ${ }^{7}$.

Aquí me referiré, entonces, a los derechos sociales de prestación, pues son los que plantean mayores dificultades con relación a su justiciabilidad. De hecho, son, en su mayor parte, los derechos que quedan excluidos del CEDH y relegados a la Carta Social Europea. Digo en su mayor parte, porque hay una excepción: el derecho la educación, que está reconocido en el artículo 2 del Protocolo 1

${ }^{4}$ Parágrafo 5. En Internet, http://www.ohchr.org/Documents/Events/OHCHR20/VDPA_ booklet_Spanish.pdf

${ }^{5}$ Vid. LAPORTA, F. (2004) «Los derechos sociales y su protección jurídica: introducción al problema» en Betegón, J. (coord.), Constitución y derechos fundamentales, Madrid: Centro de Estudios Políticos y Constitucionales, pp. 298-300.

${ }^{6}$ Sobre los derechos sociales de prestación vid. Escobar Roca, G. (2012), «Los derechos fundamentales sociales de prestación (doctrina general)» en: Escobar Roca, G. (Dir.), Derechos sociales y tutela antidiscriminatoria, Cizur Menor (Navarra): Thomson Reuters Aranzadi, pp. 459-647.

7 LAPORTA considera, también, que, entre los derechos sociales, son frecuentes los que denomina «derechos racimo», es decir, derechos en los que pueden encontrarse componentes de ambas categorías. Como ejemplo, el derecho al trabajo contiene un derecho de libertad —la libertad de ejercer una profesión — y varios derechos de prestación — derecho a un salario digno, a unas dignas condiciones de trabajo y a una prestación en caso de desempleo, entre otras. Vid. LAPORTA, F. J., «Los derechos sociales y su protección jurídica: introducción al problema», cit., pp. 300-301. 
del CEDH, si bien hay que reconocer que la jurisprudencia que se ha ocupado de este derecho se ha centrado más en su dimensión de derecho de libertad (sobre todo, en el derecho de los padres a elegir la educación que desean para sus hijos) que en su dimensión de derecho de prestación ${ }^{8}$.

Como se ha visto, la principal dificultad que plantean los derechos sociales de prestación es la relativa a su justiciabilidad. La crítica tradicional pone de manifiesto que para que un Estado pueda garantizar plenamente los derechos a la educación, a la protección de la salud, a una vivienda digna o a una protección social mínima ha de contar con unos medios económicos muy abundantes, por no decir ilimitados ${ }^{9}$. Por otra parte, se afirma también que los jueces y tribunales no deben sustituir a los gobiernos y parlamentos en la definición de las políticas públicas que traten de hacer realidad estos derechos, pues la elaboración de los Presupuestos Generales del Estado es misión de los poderes legislativo y ejecutivo, no del poder judicial ${ }^{10}$.

A pesar de ello, numerosos trabajos doctrinales tratan de justificar la aptitud de los derechos sociales de prestación para ser calificados de derechos fundamentales y para gozar de un cierto nivel de eficacia jurídica, sometida siempre a un juicio de ponderación con otros bienes y derechos ${ }^{11}$. Además, ya se garantiza habitualmente de forma universal un derecho de prestación típico, como es el

8 Santolaya Machetti, P. y Díaz Ricci, S. (2012), «Los derechos económicos, sociales y culturales y la protección de grupos vulnerables» en García RocA, J.; FERnández, P. A.; SANtolaya, P. y Canosa, R. (Eds.), El diálogo entre los Sistemas Europeo y Americano de Derechos Humanos, Cizur Menor: Civitas/Thomson Reuters, p. 276.

9 Vid. Forsthoff, E. (1986), «Problemas constitucionales del Estado social», en ABENDroth, W.; Forsthoff, E. y Dohering, K., El Estado social, Madrid: Centro de Estudios Constitucionales, Madrid.

${ }^{10}$ Con referencia a la Constitución española, Francisco Bastida argumenta bien sobre la dificultad de la consideración de los derechos sociales de prestación reconocidos en el Capítulo III del Título Primero como derechos fundamentales, si partimos de un concepto de «fundamentalidad jurídica». Vid. BASTIDA, F. J. (2008), «¿Son los derechos sociales derechos fundamentales? Por una concepción normativa de la fundamentalidad de los derechos», en VV. AA., Estudios sobre la Constitución Española. Homenaje al Profesor Jordi Solé Tura, vol. II, Madrid: Cortes Generales/ Centro de Estudios Políticos y Constitucionales, pp. 1083-1101.

11 Vid., por ejemplo, Abramovich, V. y Courtis, C. (2004), Los derechos sociales como derechos exigibles, Trotta, Madrid; Arango, R. (2005), El concepto de derechos sociales fundamentales, Bogotá: Legis; Alexy, R. (Ed.) (2007), Derechos sociales y ponderación, Madrid: Fundación Coloquio Jurídico Europeo; Carmona Cuenca, E. (2008), « ¿Los derechos sociales de prestación son derechos fundamentales?», en VV. AA., Estudios sobre la Constitución Española. Homenaje al Profesor Jordi Solé Tura, ob. cit., pp. 1103-1118; PIsArello, G. (Ed.) (2009), Los derechos sociales como derechos justiciables: Potencialidades y limites, Albacete: Bomarzo; KосH, I. E. (2009), Human Rights as Indivisible Rights. The Protection of Socio-Economic Demands under the European Convention on Human Rights, Leiden, Boston: Martinus Nijhoff; Escobar RocA, G. (Dir.) (2012), Derechos sociales y tutela 
derecho de educación básica obligatoria ${ }^{12}$. Del mismo modo, podrían garantizarse otros derechos sociales de prestación, siempre que se estableciesen unos niveles mínimos factibles ${ }^{13}$. La fijación de estos niveles mínimos es tarea principal del legislador, pero los tribunales deberían poder establecer también unos estándares básicos de protección en caso de actividad legislativa injustificadamente restrictiva o de ausencia flagrante de tal actividad en la protección de los derechos sociales de prestación ${ }^{14}$. Y en alguna ocasión lo han hecho, como veremos más adelante al estudiar la jurisprudencia del TEDH sobre derechos sociales.

\section{LAS OBLIGACIONES POSITIVAS DEL ESTADO EN LA JURISPRUDENCIA DEL TEDH}

Con relación al Convenio Europeo de Derechos Humanos, la técnica de las obligaciones positivas del Estado ha sido definida como el proceso interpretativo que permite deducir de una disposición convencional obligaciones estatales de acción que no están prescritas expresamente en tal Convenio ${ }^{15}$. El TEDH ha sido la primera instancia jurisdiccional internacional que ha reconocido la posibilidad de que los derechos convencionales (en especial, como veremos, los derechos civiles y políticos) generen no solo obligaciones negativas sino también obligaciones positivas a cargo del Estado. Pero, en esta línea argumentativa, ha recibi-

antidiscriminatoria, ob. cit. y CHATTON, G. T. (2013), Vers la pleine reconnaissance des droits économiques, sociaux et culturels, Genève: Shulthess Médias Juridiques.

12 Así lo hace la Constitución española en su artículo 27.

13 Vid. Carmona Cuenca, E. (2008), «¿Los derechos sociales de prestación son derechos fundamentales?», cit.

14 Del modo en que lo hace, por ejemplo, el Tribunal Constitucional italiano en sus Sentencias 80/2010, de 22 de febrero, y 275/2016, de 16 de diciembre, en las que ha considerado inconstitucionales las restricciones legislativas establecidas en materia de protección de alumnos con discapacidad (relativas a los profesores de apoyo y al transporte escolar) por contravenir el «núcleo indisponible de garantía» del derecho a la educación de las personas con discapacidad grave. Aunque el Tribunal reconoce un margen de discrecionalidad del legislador en la protección de los derechos fundamentales, considera que, en este caso, se ha vulnerado el núcleo esencial del derecho que debe ser respetado en todo caso. Sobre la jurisprudencia del Tribunal Constitucional español en materia de derechos sociales, vid. Díaz Crego, M. (2012), «Derechos sociales y amparo constitucional», en Revista Vasca de Administración Pública N. 94.

15 Madelaine, C. (2014), La technique des obligations positives en droit de la Convention Européenne des Droits de l'Homme, Paris: Dalloz., p. 24. 
do dos influencias fundamentales: la jurisprudencia del Tribunal Constitucional Federal Alemán y el Derecho Internacional Público general ${ }^{16}$.

Ya en el caso Lingüistico Belga ${ }^{17}$, tanto la Comisión (Informe de 24 de junio de 1965) como el TEDH (Sentencia de 23 de julio de 1968) establecieron que los derechos reconocidos en el Convenio podían generar obligaciones positivas, obligaciones de hacer a cargo de los Estados ${ }^{18}$. En este caso, el Gobierno belga alegaba que, según la concepción liberal clásica, los derechos civiles y políticos reconocidos en el Convenio tenían una naturaleza distinta a la de los derechos sociales reconocidos en la Carta Social Europea. Así, mientras aquéllos solo generaban obligaciones negativas por parte de los Estados para proteger la libertad, éstos generaban auténticas obligaciones positivas. Precisamente por esta razón el sistema de protección de estos instrumentos normativos era distinto y más judicializado el del Convenio Europeo.

Pero, en este caso, los demandantes habían alegado que el derecho a la educación del artículo 2 Protocolo $1 \mathrm{CEDH}$ (en realidad, un derecho social de prestación) no solo exigía obligaciones negativas del Estado, sino verdaderas obligaciones «de hacer». El TEDH parece darles la razón. En palabras de la Comisión, que el Tribunal hace suyas:

«Los derechos reconocidos por el Convenio no son todos "negativos" hay que examinar cada materia y cada disposición de forma independiente sin dejarse llevar por una doctrina "de cierta edad" — la doctrina clásica de las libertades individuales- que "puede conservar un cierto valor filosófico", pero "no tiene carácter normativo" ${ }^{19}$.

Más adelante, el Tribunal establece:

«La formulación negativa significa (...) que las Partes Contratantes no reconocen un derecho a la educación que les obligue a mantener a su costa o subvencionar un sistema de enseñanza de una forma o en una escala determinadas. De ello no cabe deducir, sin embargo, que el Estado carezca de toda obligación positiva para asegurar el respeto de este derecho, tal como el artículo 2 del Protocolo lo protege. Puesto que un «derecho» existe, éste es garantizado, en virtud del artículo 1 del Convenio, a toda persona dependiente de la jurisdicción de un Estado contratante.»

${ }^{16}$ No puedo extenderme aquí en estas influencias sobre el TEDH, puede verse: MADELAINE, C. (2014), La technique des obligations positives..., ob. cit., pp. 35 y ss.

${ }^{17}$ Caso relativo a ciertos aspectos del régimen lingüístico de la enseñanza en Bélgica.

18 Vid. Madelaine, C. (2014), La technique des obligations positives..., ob. cit., p. 1.

19 Caso Lingüístico Belga, STEDH de 23 de julio de 1968, Fundamentos de Derecho I-A-1. 
Este reconocimiento de las obligaciones positivas se consolidó en los famosos casos Marckx ${ }^{20}$ y Airey ${ }^{21}$, de 1979. En el caso Marckx, el TEDH afirmó que el derecho a la vida familiar del artículo $8 \mathrm{CEDH}$ incluía unas obligaciones positivas del Estado para garantizar que las demandantes pudieran desarrollar una «vida familiar normal», lo que suponía la integración de la menor en su familia desde el momento de su nacimiento. Afirmaba que el Estado podía satisfacer esta obligación con los medios que juzgase más oportunos pero, como en este caso no lo había realizado, consideró que se había vulnerado este derecho.

En el caso Airey se contienen interesantes reflexiones sobre el contenido prestacional de los derechos civiles y políticos y se afirma que éstos no suponen únicamente obligaciones negativas del Estado sino también deberes positivos de éste para asegurar su efectividad. En este caso, una mujer con tres hijos demandó al Estado por no haberle permitido acceder a los tribunales para defenderse de los malos tratos de su esposo contra ella y sus hijos. En concreto, el Tribunal establece que «el deber de asegurar el derecho de acceso a los Tribunales entra en esta categoría de deberes positivos del Estado» ${ }^{22}$. Y condena al Estado por no haber cumplido con estos deberes positivos derivados del artículo $6.1 \mathrm{y}$, nuevamente, del derecho a la vida familiar del artículo $8 \mathrm{CEDH}$.

A pesar de que el origen de la técnica de las obligaciones positivas del Estado se sitúa en una interpretación del derecho a la educación del artículo 2 Protocolo $1 \mathrm{CEDH}^{23}$, el mayor desarrollo de este concepto se ha producido con relación a los derechos civiles y políticos reconocidos en el Convenio. Madelain afirma que no deja de ser una herramienta de adaptación de la norma convencional a los Estados liberales europeos contemporáneos. No solo no desafía el liberalismo, sino que tiende a asegurar su promoción. Convierte al Estado en protector de las libertades ${ }^{24}$.

Los derechos convencionales a los que se ha aplicado en mayor número de ocasiones esta técnica han sido: el derecho a la vida (art. 2), el derecho a no sufrir torturas (art. 3), el derecho a la libertad y seguridad (art. 5), el derecho a un juicio justo (art. 6) y el derecho a la vida privada y familiar (art. 8). De estos derechos se han derivado obligaciones positivas del Estado relativas a la investigación de asesinatos y torturas, la planificación y control de las operaciones de las fuerzas de seguridad, la medidas de protección de los detenidos, la provisión de condiciones adecuadas para detenidos y presos, las medidas para evitar las

20 Caso Marckx c. Bélgica, de 13 de junio de 1979.

${ }^{21}$ Caso Airey c. Irlanda, de 9 de octubre de 1979.

22 Parágrafo 25.

23 En concreto, en el caso Lingüístico Belga, que se acaba de comentar.

24 Madelaine, C. (2014), La technique des obligations positives..., ob. cit., p. 467. 
desapariciones durante la custodia de detenidos, la investigación de las desapariciones, los deberes del Estado para garantizar un juicio justo, el reconocimiento oficial de las personas transexuales, el establecimiento de la paternidad, la reunión de los niños con sus padres, el respeto del estilo de vida de las minorías, la protección del domicilio y un largo etcétera ${ }^{25}$.

En menor medida se ha aplicado también a las libertades de pensamiento, expresión, reunión y asociación, al derecho a un recurso efectivo y a la prohibición de discriminación (arts. 9, 10, 11, 13 y 14 CEDH) y, así, se han reconocido obligaciones positivas referentes a la protección de la libertad de expresión o de las asambleas pacíficas o a la provisión de recursos internos frente a las violaciones de los derechos convencionales.

Como justificación de la introducción de esta técnica de las obligaciones positivas del Estado, el Tribunal ha invocado dos principios generales: En primer lugar, la obligación general de los Estados parte, establecida en el artículo 1 $\mathrm{CEDH}$, de reconocer a toda persona dependiente de su jurisdicción los derechos y libertades reconocidos en el Convenio y, en segundo lugar, el principio de interpretación efectiva, que exige que los derechos sean aplicados de manera práctica y efectiva, no de forma teórica o ilusoria ${ }^{26}$. De forma más clara, el Tribunal ha establecido estas obligaciones con relación a las personas sobre las que el Estado posee un control más pleno y, por ello, tienen menos autonomía para hacer valer sus derechos por sí mismas (población reclusa, personas con discapacidad bajo tutela del Estado... $)^{27}$.

A pesar de su frecuente utilización, el concepto de obligaciones positivas del Estado no deja de ser un concepto bastante huidizo. En la doctrina se han puesto de manifiesto las incoherencias de la jurisprudencia del TEDH sobre esta técnica y la difícil distinción entre obligaciones negativas y obligaciones positivas en la mayoría de los casos. Madelaine opina que la técnica de las obligaciones positivas solo podría aplicarse en aquellos supuestos en que está en juego una actuación del Estado consistente en una ejecución «física» o concreta como, por ejemplo, la obligación de investigar denuncias de muerte, torturas o desapariciones. Pero si se trata de obligaciones estatales de aprobar un marco legislativo

25 El número de sentencias que establecen obligaciones positivas derivadas de estos derechos es incontable. Vid. una buena recopilación jurisprudencial en MowBray, A. R. (2004), The development of Positive Obligations under the European Convention on Human Rights, Oxford: Hart Publishing.

26 Así lo estableció el TEDH en el mencionado caso Airey c. Irlanda.

27 KennA, P. (2009), «El derecho a la vivienda en Europa: deberes positivos y derechos exigibles (según la jurisprudencia del Tribunal Europeo de Derechos Humanos», en Revista de Derecho Político, UNED, n. ${ }^{\circ} 74$, p. 488. 
o una actuación administrativa o incluso una decisión jurisdiccional no es fácil distinguir si estamos en presencia de una obligación positiva o negativa ${ }^{28}$.

Con todo, también se ha puesto de manifiesto en la doctrina la importancia de esta técnica para garantizar los derechos humanos reconocidos en el Convenio. Xenos pone de manifiesto que es la primera vez en la historia de la Humanidad en que una persona (y no solo un ciudadano) puede plantear un conflicto ante un tribunal nacional o internacional en el que se discuta cuáles son las concretas obligaciones del Estado para proteger los derechos y en el que se pueda condenar al Estado por no haber adoptado las medidas de protección adecuadas ${ }^{29}$. Esto supone un desplazamiento de la iniciativa legislativa del legislador al pueblo. Pero también supone la atribución de una cierta potestad legislativa al Tribunal de Estrasburgo. Se ha dicho que el Juez europeo sustituye a los Estados partes y a los legisladores nacionales en tanto que creador de Derecho ${ }^{30}$.

En cuanto a los concretos derechos que generan obligaciones positivas del Estado, el Tribunal Europeo ha aplicado esta técnica interpretativa, fundamentalmente, a los derechos civiles y políticos reconocidos en el Convenio, como hemos visto. En general, puede afirmarse que la jurisprudencia del TEDH ha rechazado consagrar obligaciones de prestación social sobre la base de esta argumentación ${ }^{31}$. Volveremos sobre esta cuestión más adelante, al estudiar cómo se ha utilizado en la jurisprudencia europea el concepto de obligaciones positivas del Estado para proteger los derechos sociales de prestación ${ }^{32}$.

\section{LAS TÉCNICAS DE PROTECCIÓN DE LOS DERECHOS SOCIALES DE PRESTACIÓN EN LA JURISPRUDENCIA DEL TEDH}

\subsection{Planteamiento general}

Como se ha visto, el Convenio Europeo de Derechos Humanos protege esencialmente derechos civiles y políticos, mientras que los derechos económicos y sociales son reconocidos por la Carta Social Europea. Aunque en el seno del Consejo de Europa ha habido varios intentos de incluir estos últimos derechos

${ }^{28}$ Con una argumentación más extensa que la que puedo ofrecer aquí, vid. Madelaine, C. (2014), La technique des obligations positives..., ob. cit., pp. 467-470.

29 Xenos, D. (2012), The Positive Obligations of the State under the European Convention of Human Rights, London and New York: Routlege, pp. 204-205.

30 Madelaine, C. (2014), La technique des obligations positives..., ob. cit., p. 467.

31 Idem., p. 470.

32 Vid. más adelante, epígrafe 5. 
en el texto del Convenio, no se ha llegado a un acuerdo sobre esta posibilidad ${ }^{33}$. Más bien se han puesto de manifiesto las dificultades que plantearía otorgar al TEDH la facultad de decidir sobre la justiciabilidad de derechos que implican importantes obligaciones prestacionales de los Estados.

Las únicas excepciones a esta ausencia de derechos económicos y sociales en el CEDH serían el reconocimiento de la libertad sindical como parte del contenido del derecho de asociación del artículo $11 \mathrm{CEDH}$ (por tanto, un derecho social de libertad) y el derecho a la educación (este sí un derecho social de prestación) en el artículo 2 del Protocolo 1 CEDH. Por esta razón, en general, el TEDH (y antes la Comisión) han declarado inadmisibles las demandas fundadas en estos derechos sociales de prestación ${ }^{34}$.

Sin embargo, ya a partir del mencionado caso Airey c. Irlanda (de 1979), el Tribunal ha entendido, en numerosas ocasiones, que no es posible trazar una separación absoluta entre los derechos civiles y políticos y los derechos económicos y sociales:

«Aunque el Convenio establece una serie de derechos de carácter esencialmente civil y político, algunos de ellos tienen implicaciones de naturaleza económica o social... El mero hecho de que una interpretación del Convenio pudiera extenderse hacia la esfera de los derechos sociales y económicos no supondría un factor decisivo contra dicha interpretación; no existe una separación drástica entre esa esfera y lo recogido por el Convenio.»

De esta forma, a pesar del tenor literal del Convenio, en múltiples sentencias el TEDH ha entrado a conocer demandas que tenían un importante contenido económico y social y, es más, ha llegado a reconocer auténticos derechos sociales de prestación a partir de los derechos que sí están reconocidos en el texto del

33 Sobre estos intentos, puede verse: Morte Gómez, C. y Salinas Alcega, S. (2009), «Los derechos económicos y sociales en la jurisprudencia del Tribunal Europeo de Derechos Humanos», en Embid Irujo, A. (Dir.), Derechos económicos y sociales, Madrid: Iustel, pp. 366-377. Estos autores no consideran recomendable la incorporación de los derechos económicos y sociales al CEDH, pues se incrementaría en gran medida el volumen de trabajo, ya de por sí muy considerable, del Tribunal Europeo.

34 Así lo hace el TEDH, por ejemplo, en la decisión de inadmisibilidad Salvetti c. Italia, de 9 de julio de 2002. Vid. Sudre, F. (2003) «La protection des droits sociaux par la Cour Européenne des Droits de l'Homme: Un exercice de “Jurisprudence fiction”? », Revue Trimestrielle des Droits de l'Homme, n. ${ }^{\circ} 55$, p. 755 . 
Convenio. Para ello, ha utilizado diversos mecanismos de protección indirecta ${ }^{35}$, realizando lo que se ha denominado una interpretación evolutiva ${ }^{36}$ del CEDH.

Una parte de la doctrina se muestra, en términos generales, partidaria de esta extensión de la protección ofrecida por el TEDH a los derechos sociales. En concreto, Sudre afirma que esta extensión es conveniente y ello tanto por razones de principio como por razones de oportunidad ${ }^{37}$. En cuanto a las primeras, expone que no hay que perder de vista la indivisibilidad de los derechos humanos y que tanto los derechos civiles y políticos como los económicos y sociales son igualmente inherentes a la dignidad humana y deben ser protegidos. En cuanto a las razones de oportunidad, pone de manifiesto que la aprobación de la Carta de los Derechos fundamentales de la Unión Europea el 18 de diciembre de $2000^{38}$ supone la introducción de un Documento que reconoce de forma indiferenciada los derechos civiles y políticos y los derechos económicos y sociales $^{39}$. Si el Convenio Europeo quiere seguir siendo un texto de vanguardia en la protección de los derechos humanos en Europa, no debe descartar, en principio, la protección de ninguno de estos derechos, incluidos los económicos y sociales.

Sin embargo, también se ponen de manifiesto en la doctrina las dificultades que conlleva la extensión de la competencia del TEDH a la protección de los derechos económicos y sociales y, muy particularmente, a los derechos sociales de prestación. Se dice que, para garantizar estos derechos, es preciso contar con

35 Vid. López Guerra, L. (2014), «La protección de los derechos económicos y sociales en el Convenio Europeo de Derechos Humanos» y PÉrez Alberdi, M. R. (2014), «La protección de los derechos sociales en la jurisprudencia del Tribunal Europeo de Derechos Humanos», ambos en Terol Becerra, M. y Jimena Quesada, L. (Dirs.), Tratado sobre protección de derechos sociales, Valencia: Tirant lo Blanch, pp. 297-317 y 319-332 respectivamente. Pérez Alberdi concluye que la protección de los derechos sociales ofrecida por el Tribunal Europeo es insuficiente y que sigue siendo necesaria la garantía de la Carta Social Europea.

36 Vid. Daugareilh, I. (2001), «La Convention Européenne de sauvegarde des droits de l'homme et des libertés fondamentales et la protection sociale», Revue Trimestrielle de Droit Européenne, n. ${ }^{\circ} 1$, p. 126.

37 Sudre, F. (2003) La protection des droits sociaux... , cit., pp. 755-757.

38 Texto al que el Tratado de Lisboa, aprobado el 13 de diciembre de 2007, otorga el mismo valor jurídico de los Tratados constitutivos de la Unión Europea.

39 Aunque en la versión de la Carta de 2007 se introduce la distinción entre derechos y principios (arts. 51 y 52) y se otorga una menor eficacia jurídica a estos últimos por lo que se refiere a su invocabilidad ante los tribunales. Es cierto que no se determina claramente qué preceptos reconocen derechos y cuáles establecen principios, con una menor justiciabilidad, pero, en una interpretación sistemática y teniendo en cuenta el Derecho comparado europeo, los derechos sociales de prestación entrarían, en general, en la categoría de principios. Vid. las Conclusiones del Abogado General Pedro Cruz Villalón presentadas el 18 de julio de 2013 en el asunto C-176-12 del Tribunal de Justicia de la Unión Europea. 
medios económicos suficientes y que son los Estados los que deben establecer la política económica en el interior del país, en particular, es misión de los poderes legislativo y ejecutivo la definición de esa política económica. En atención a estas consideraciones, el Tribunal Europeo se ha mostrado, en general, muy cauteloso a la hora de establecer la violación de un derecho social de prestación por parte del Estado ${ }^{40}$. En general, ha adoptado una posición de deferencia (o autocontención judicial) y ha otorgado un amplio margen de apreciación a los Estados ${ }^{41}$.

Así lo hizo, por ejemplo, en la decisión de inadmisibilidad Pentiacova y otros c. Moldavia, de 4 de enero de 2005, en la que decidía sobre una prestación sanitaria. Los demandantes se habían quejado de la insuficiente financiación pública en el tratamiento de la hemodiálisis. Aunque el Tribunal reconoció que el asunto podría entrar en el ámbito del derecho a la vida privada y familiar del artículo $8 \mathrm{CEDH}$, inadmitió la demanda, pues consideró que en esta materia son los Estados quienes deben configurar las prioridades a la vista de las limitaciones presupuestarias. De forma muy gráfica se expresó también el Tribunal en el caso Jane Smith c. Reino Unido, Sentencia de 18 de enero de 2001, sobre el derecho a la vivienda: «El artículo 8 no reconoce el derecho a obtener un domicilio, como tampoco lo hace la jurisprudencia del Tribunal... Que el Estado provea fondos para permitir a todos tener un hogar es un asunto político y no una decisión judicial» ${ }^{42}$.

A pesar de ello, en algunos casos el TEDH se ha mostrado más inclinado a reconocer la vulneración de un derecho social de prestación derivado de uno de los derechos reconocidos en el Convenio. Esto ha sucedido en determinadas circunstancias que podríamos sintetizar como sigue: a) cuando se han producido unos daños que son responsabilidad directa del Estado; b) cuando se trata de personas que se encuentran bajo la custodia del Estado, como la población reclu-

40 Vid., entre otros, Binder, C. y Schobesberger, T. (2015), «El Tribunal Europeo de Derechos Humanos y los derechos sociales ¿Nuevas tendencias en la jurisprudencia?», en UGARtemendía Eceizabarrena, J. I.; Saiz Arnáiz, A. y Morales Antoniazzi, M., La garantía jurisdiccional de los derechos humanos. Un estudio comparado de los sistemas regionales de tutela: europeo, interamericano y africano, Oñati: Instituto Vasco de Administración Pública, p. 104 y Clements, L. and Simmons, A. (2008), «European Court of Human Rights. Sympathetic Unease» en LANGFORD, M. (Ed.), Social Rights Jurisprudence. Emerging Trends in International and Comparative Law, Cambridge University Press, p. 409.

41 Sobre la aplicación por el TEDH de la doctrina del margen de apreciación, vid. GARCía Roca, J. (2010), El margen de apreciación en la interpretación del Convenio Europeo de Derechos Humanos. Soberanía e integración, Madrid: Civitas.

42 Parágrafos 105 y 106. Y lo reitera en el caso Chapman c. Reino Unido, de la misma fecha. 
sa, y c) cuando se trata de personas especialmente vulnerables, como las minorías étnicas o las personas con discapacidad ${ }^{43}$.

Para ello ha utilizado diferentes mecanismos, algunos de los cuales (los que considero más importantes) trataré de sintetizar a continuación ${ }^{44}$ : a) aplicación de la prohibición de discriminación del artículo $14 \mathrm{CEDH}$ a determinadas prestaciones sociales; b) ampliación del contenido de varios derechos reconocidos en el Convenio y c) aplicación de la doctrina de las obligaciones positivas del Estado a los derechos sociales de prestación.

Ha sido particularmente fructífera la combinación de las técnicas b) y c), es decir la aplicación de la doctrina de las obligaciones positivas del Estado a algunos derechos sociales de prestación no reconocidos en el Convenio, sino derivados de otros derechos civiles y políticos que sí aparecen expresamente en el mismo. Después de una breve referencia a esta ampliación del contenido de los derechos clásicos, en el siguiente epígrafe me referiré a la doctrina de las obligaciones positivas del Estado como técnica de protección de los derechos sociales de prestación.

\subsection{Aplicación de la probibición de discriminación del artículo 14 CEDH a determinadas prestaciones sociales}

Este mecanismo constituye una interpretación avanzada y ya consolidada de la prohibición de discriminación del artículo $14 \mathrm{CEDH}$. Como es sabido, este artículo garantiza la prohibición de discriminación «en el goce de los derechos reconocidos» en el propio Convenio. Una reiterada jurisprudencia del Tribunal de Estrasburgo ha entendido que esta cláusula no puede ser entendida de forma autónoma y solo puede ser alegada en combinación con otro artículo del Conve-

43 Vid. Binder, C. y Schobesberger, T. (2015), El Tribunal Europeo de Derechos Humanos y los derechos sociales..., cit., pp. 109-110.

${ }^{4}$ Otros mecanismos utilizados por el TEDH para proteger indirectamente derechos sociales de prestación han sido: a) la interpretación extensiva del derecho a un proceso equitativo del artículo $6 \mathrm{CEDH}$ y b) la interpretación de algunos derechos sociales de prestación como límites a derechos reconocidos en el Convenio. Vid., por ejemplo, Sudre, F. (1998), «La "permeabilité” de la Convention Européenne des Droits de l'Homme aux droits sociaux», en Pouvoir et Liberté. Études offertes à Jacques Mougeon, Bruxelles: Bruylant; Malinverni, G. (2008), «The Protection of Social Rights in the Case Law of the European Court of Human Rigths», en Hanschel, D.; Graf von Kielmansegg, S.; Kischel, U. und Lorz, R. A. (Hrsg.), Praxis des internationalen Menschenrechtsschutzes — Entwickung und Perspectiven, Stuttgart: Richard Boorberg Verlag y MORTE Gómez, C. y Salinas Alcega, S. (2009), Los derechos económicos y sociales..., cit. 
nio ${ }^{45}$. Esto significa, en principio, que, si se trata de un derecho social de prestación diferente del derecho a la educación del artículo 2 del Protocolo 1, no podrá serle aplicada la cláusula del artículo $14 \mathrm{CEDH}$.

En el caso Gaygusuz c. Austria, de 16 de septiembre de 1996, el demandante alegaba discriminación por razón de nacionalidad en el disfrute de una prestación económica de urgencia. Era muy dudoso que esta prestación pudiera encuadrarse en alguno de los derechos reconocidos en el CEDH. Sin embargo, el Tribunal interpretó que se trataba un derecho patrimonial y que, como tal, formaba parte del ámbito de aplicación del derecho a la propiedad privada reconocido en el artículo 1 del Protocolo 1 del Convenio. A partir de ahí, el TEDH apreció vulneración del artículo 1 Protocolo 1 en combinación con el artículo 14 CEDH en la denegación de la prestación al demandante por razón de su nacionalidad. A partir de esta Sentencia, la doctrina consideró que esta interpretación, si se consolidaba, podría suponer la incorporación de un buen número de derechos sociales de prestación al sistema de protección del Convenio Europeo ${ }^{46}$.

Con posterioridad, se ha reiterado esta interpretación relativa al derecho a recibir prestaciones económicas en los casos Wessels-Bergervoet contra Holanda, 4 de junio de 2002, y Willis contra Reino Unido, de 11 de junio de 2002, (ambos relativos a pensiones de viudedad y discriminación por razón de género). También en el caso Koua Poirrez contra Francia, de 30 de septiembre de 2003, en el que se aprecia violación del artículo 14 en combinación con el artículo 1 del Protocolo $1 \mathrm{CEDH}$ provocada por la negativa a conceder una prestación por incapacidad a un solicitante extranjero por motivo de nacionalidad.

La aprobación del Protocolo n. 12 al CEDH en 2000 supuso la extensión de la prohibición de discriminación a todos los derechos, tanto del Convenio como de la legislación interna de los Estados. En un trabajo de 2003, Sudre consideraba que el Protocolo 12 estaba llamado a sustituir al artículo $14 \mathrm{CEDH}$, por tratarse de una lex specialis sobre igualdad y prohibición de discriminación ${ }^{47}$. También afirmaba que, con la aplicación de este Protocolo, los derechos sociales podrían ser plenamente protegidos por el Tribunal Europeo. Sin embargo, esta interpretación no ha sido incorporada por el Tribunal. Por una parte, hasta la

45 Carmona Cuenca, E. (2014), «La prohibición de discriminación. Nuevos contenidos (art. 14 y Protocolo n. ${ }^{\circ}$ 12», en: García Roca, J. y Santolaya, P. (Coords.), La Europa de los Derechos. El Convenio Europeo de Derechos Humanos, Madrid: Centro de Estudios Políticos y Constitucionales (3. ${ }^{\text {e edición). }}$

46 Sudre, F. (1998), La «permeabilité» de la Convention Européenne..., cit., pp. 474-475. Vid., también: Carmona Cuenca, E. (2014), La probibición de discriminación..., cit. y Santolaya MaChetTi, P. y Díaz Ricci, S. (2012), Los derechos económicos, sociales y culturales..., cit., pp. 285-287.

47 Sudre, F. (2003), La protection des droits sociaux..., cit., pp. 774-779. 
fecha, la aplicación de este Protocolo ha sido excepcional ${ }^{48}$. Y, por otra parte, como se ha puesto de manifiesto en la doctrina, el Protocolo 12 no atribuye al TEDH la competencia para verificar si un Estado ha reconocido y protege un derecho social, sino únicamente para pronunciarse respecto al derecho a no sufrir discriminación en el disfrute de dicho derecho social ${ }^{49}$.

En los últimos años, y como consecuencia de la crisis económica generaliza$\mathrm{da}$, se han presentado numerosas demandas ante el TEDH contra los recortes de prestaciones sociales y, en concreto, de las pensiones. Amparándose en la interpretación que hemos visto, los demandantes alegaban violación del artículo 1 Protocolo 1 en combinación con el artículo 14 CEDH. Sin embargo, el Tribunal ha mantenido una postura más restringida en el reconocimiento de vulneraciones en estos $\operatorname{casos}^{50}$. Así, por ejemplo, en las decisiones de inadmisión Frimu y otros c. Rumanía, de 7 de febrero y de 13 de noviembre de 2012, se afirma que las circunstancias económicas y sociales pueden justificar la reducción de las prestaciones sociales y que a estas reducciones debe aplicarse el principio de proporcionalidad.

\subsection{Ampliación del contenido de varios derechos reconocidos en el Convenio}

En su jurisprudencia, el TEDH ha llevado a cabo una ampliación del contenido inicial de los derechos del Convenio para incluir nuevas facetas de los mismos, algunas de las cuales constituyen auténticos derechos sociales prestacionales. No solo el derecho de propiedad del artículo 1 del Protocolo $1 \mathrm{CEDH}$ ha servido para este fin, también otros preceptos del Convenio han sido utilizados para proteger determinados derechos sociales de prestación. En particular, el TEDH ha argumentado en base al derecho a la vida (art. 2), la prohibición de la tortura y de los tratos inhumanos y degradantes (art. 3) y el derecho a la vida privada y familiar (art. 8) para proteger el derecho a la protección de la salud, a la vivienda o a la protección social, entre otros.

48 Sobre todo, debido a que este Protocolo no ha sido ratificado por todos los Estados parte del Convenio. La única vez que el TEDH ha considerado vulnerado el artículo 1 del Protocolo n. ${ }^{\circ} 12$ ha sido en el caso Sejdic y Finci c. Bosnia Hercegovina, de 22 de diciembre de 2009, en un caso de discriminación étnica relativa a la posibilidad de concurrir a unas elecciones y, aun así, se declaró vulnerado también el artículo 14 en combinación con el artículo 3 del Protocolo CEDH.

49 Morte Gómez, C. y Salinas Alcega, S. (2009), «Los derechos económicos y sociales..., cit., pp. 388-391.

${ }_{50}$ Vid. López Guerra, L. (2015), «Crisis económica y derechos humanos. Una nota de jurisprudencia», Teoría y Realidad Constitucional, UNED, N. ${ }^{0}$ 36, pp. 404-405. 
El derecho a la vida del artículo $2 \mathrm{CEDH}$ ha sido utilizado por el Tribunal Europeo en combinación con la doctrina de las obligaciones positivas del Estado para salvaguardar — en mayor o menor medida - el derecho a la protección de la salud en los casos Calvelli y Ciglio c. Italia, de 17 de enero de 2002, y Oyal c. Turquía, de 23 de marzo de 2010. También se ha realizado esta interpretación (considerar incluidos en el ámbito de protección del artículo $2 \mathrm{CEDH}$ nuevos contenidos sociales) en la decisión de inadmisión Nitecki c. Polonia, de 21 de marzo de 2001, aunque finalmente no se otorgase la protección.

La prohibición de la tortura y de los tratos inhumanos y degradantes del artículo $3 \mathrm{CEDH}$ ha servido de base también para preservar el derecho a la protección de la salud en varios casos relativos a las condiciones sanitarias e higiénicas de las prisiones ${ }^{51}$, como veremos en el siguiente epígrafe.

Es más discutible considerar que se haya utilizado el artículo $3 \mathrm{CEDH}$ para garantizar la protección contra la pobreza. La interpretación tradicional mantenía un concepto muy riguroso de «tratos inhumanos y degradantes», que no incluía la pobreza. Así, en la decisión Volsem c. Bélgica, de 9 de mayo de 1990, el Tribunal inadmitió una demanda basada en el artículo $3 \mathrm{CEDH}$, considerando que el corte de electricidad a una madre soltera de tres hijos por falta de pago no podía incluirse en el ámbito de aplicación de este precepto.

Sudre se preguntaba en 2003 si el concepto de «tratos degradantes» podría aplicarse a las condiciones de vida miserables que impone la pobreza extrema y la exclusión social (contempladas en el artículo 30 de la Carta Social Europea revisada). El autor afirmaba que esta posibilidad no era del todo ilusoria a la vista de la decisión de inadmisibilidad Larioshina c. Rusia de 23 de abril de 2002, en la cual se afirmaba que:

«El Tribunal considera que una demanda sobre la cuantía totalmente insuficiente de una pensión y de otras prestaciones puede, en principio, caer en el ámbito de aplicación del artículo 3 del Convenio, que prohíbe los tratos inhumanos y degradantes. Sin embargo, sobre la base de los antecedentes del caso, el Tribunal no encuentra ningún indicio de que la cuantía de la pensión de la demandante y de las prestaciones sociales adicionales haya causado un daño en su salud física o mental capaz de alcanzar el mínimo de gravedad para caer en el ámbito de aplicación del artículo 3 del Convenio.»

Sin embargo, esta interpretación no se ha reiterado en casos posteriores. Al contrario, como hemos visto en el apartado 4.2, ante las demandas por las reducciones de las pensiones de los últimos años, el Tribunal ha opuesto las «circunstancias económicas y sociales» como justificación de los «recortes».

${ }^{51}$ Por ejemplo, en el caso Ananyev y otros c. Rusia, de 10 de enero de 2012. 
El derecho a la vida privada y familiar ha servido de base para ciertas argumentaciones en las que se ampliaba su ámbito de protección para incluir contenidos relativos a la protección de la salud (caso Roche c. Reino Unido, de 19 de octubre de 2005), la vivienda (decisión de inadmisibilidad Marzari c. Italia, de 4 de mayo de 1999 y caso Winterstein y otros c. Francia, de 17 de octubre de 2013) o la protección de las personas con discapacidad (decisión de inadmisibilidad La Parola y otros c. Italia, de 30 de noviembre de 2000), aunque no siempre se haya otorgado la protección.

\section{EN ESPECIAL: LA PROTECCIÓN DE LOS DERECHOS SOCIALES DE PRESTACIÓN A TRAVÉS DE LA DOCTRINA DE LAS OBLIGACIONES POSITIVAS DEL ESTADO}

Como hemos visto más arriba ${ }^{52}$, la doctrina de las obligaciones positivas del Estado, en la interpretación del TEDH, supone que los derechos garantizados en el Convenio no imponen únicamente a los Estados obligaciones de no injerencia, sino que también establecen obligaciones de realizar determinadas acciones (adoptar una legislación o determinadas políticas o llevar a cabo actuaciones materiales...). Esta doctrina se ha aplicado fundamentalmente a los derechos civiles y políticos reconocidos en el CEDH, como también se ha puesto de manifiesto.

En principio, parecería que esta técnica interpretativa está particularmente indicada para proteger los derechos sociales de prestación y, de hecho, la primera vez que el TEDH argumentó en base a ella fue en un caso sobre el derecho a la educación ${ }^{53}$. López Guerra se pregunta si la doctrina de las obligaciones positivas del Estado aplicada a algunos derechos clásicos, como el derecho a la vida (art. 2 CEDH), el derecho a no sufrir torturas ni tratos inhumanos y degradantes (art. $3 \mathrm{CEDH}$ ) o el derecho a la vida privada y familiar (art. $8 \mathrm{CEDH}$ ), podría servir para garantizar unas prestaciones sociales mínimas, unas condiciones básicas de subsistencia (mínimo vital, atención sanitaria, vivienda... ${ }^{54}$.

Sin embargo, en las ocasiones en que se ha utilizado con relación a estos derechos, el Tribunal se ha mostrado muy cauto, no la ha aplicado con el mismo

52 Epígrafe 3.

53 En el caso Lingüístico Belga, como se ha visto.

54 López Guerra, L. (2014), La protección de los derechos económicos y sociales..., cit., pp. 314316 y López Guerra, L. (2015), Crisis económica y derechos humanos..., cit., pp. 404-405. 
«entusiasmo» que con relación a los derechos civiles y políticos ${ }^{55}$. Y esto, como pone de manifiesto Sudre, es expresión de una «voluntad deliberada» ${ }^{56}$. En estos casos, el Tribunal de Estrasburgo destaca el amplio margen de apreciación de los Estados en cuanto a la adopción de las políticas sociales y mantiene una posición de deferencia con respecto a materias que requieren decisiones importantes sobre la distribución de recursos ${ }^{57}$.

En la decisión de inadmisibilidad Zehnalova y Zehnal c. República Checa, de 14 de mayo de 2002, el TEDH realiza unas interesantes afirmaciones de carácter general sobre las obligaciones positivas derivadas del artículo $8 \mathrm{CEDH}$. Afirma que la frontera entre éstas y las obligaciones negativas inherentes a este precepto es difusa y que, en cualquier caso, hay que tener en cuenta el equilibrio entre los derechos individuales y los intereses generales. Por ello, otorga un margen de apreciación al Estado. De forma muy significativa, se pregunta por la frontera entre los derechos del Convenio y los derechos de la Carta Social Europea para responder que, aunque ciertamente, la continua evolución de la sociedad europea requiere cada vez mayores esfuerzos de los gobiernos nacionales para hacer frente a los déficits de protección de derechos sociales y para intervenir cada vez más en las relaciones entre particulares, existen unos límites en cuanto al reconocimiento de las obligaciones positivas del Estado. En este caso, la demandante alegaba que la falta de accesos especiales para personas con discapacidad a ciertos edificios abiertos al público vulneraba el artículo $8 \mathrm{CEDH}$ y que existían obligaciones positivas del Estado para garantizar estos accesos. El Tribunal consideró que solo cuando la deficiencia afectase al núcleo del derecho a la vida privada y familiar de la interesada (a su desarrollo personal y a sus relaciones con otras personas) podría hablarse de obligaciones positivas del Estado, lo que no sucedía en este caso, y consideró inaplicable el artículo $8 \mathrm{CEDH}$.

La técnica de las obligaciones positivas del Estado ha sido aplicada, con mayor o menor fortuna, a algunos derechos sociales de prestación. Aquí me referiré a dos derechos que han sido objeto de diversos pronunciamientos del TEDH: protección de la salud y vivienda.

55 Sudre habla de «ilusión óptica» (trompe l'oeil) para referirse a la doctrina de las obligaciones positivas del Estado con relación a los derechos sociales. Vid. Sudre, F. (1998), La «permeabilité» de la Convention Européenne..., cit., p. 468.

56 Sudre, F. (2003), La protection des droits sociaux..., cit., p. 764.

57 Binder, C. y Schobesberger, T. (2015), El Tribunal Europeo de Derechos Humanos y los derechos sociales..., cit., p. 106. 


\subsection{El derecho a la protección de la salud}

Entre las sentencias que se han ocupado del derecho a la protección de la salud, se pueden distinguir las que se refieren a la asistencia sanitaria o a prestaciones sanitarias y las que se refieren a la actuación del Estado para prevenir daños a la salud causados por catástrofes medioambientales o industrias contaminantes y peligrosas. Mientras que la definición de las obligaciones positivas relacionadas con esta actividad preventiva se ha realizado de manera más clara y completa, la definición de un pretendido derecho a la asistencia sanitaria no ha llegado a formularse de modo concluyente, salvo en algunos casos muy concretos, como veremos.

Sobre las obligaciones positivas del Estado con relación a la prevención de daños causados por catástrofes medioambientales, se ha pronunciado el TEDH en la sentencia Budayeva y otros c. Rusia, de 20 de marzo de 2008, en la que reconoció vulneración del artículo $2 \mathrm{CEDH}$ por la falta de protección del Estado en un caso de deslizamientos de tierras que habían causado la muerte de varias personas. Y, con relación a los daños causados por industrias o actividades contaminantes o peligrosas, se pronunció el Tribunal en el caso López Ostra c. España, de 9 de diciembre de $1994^{58}$. En esta sentencia se reconoció la vulneración del artículo $8 \mathrm{CEDH}$ debido a la falta de protección estatal frente a las emanaciones de humos, olores y ruidos de una industria situada junto a la vivienda de la demandante, que había causado problemas de salud a su familia.

Una síntesis de las obligaciones positivas estatales en estos casos puede verse en el caso Tatar c. Rumanía, de 27 de enero de 2009, que trae causa de un grave accidente ecológico causado por una industria minera. En él se enumeran las obligaciones estatales en la materia derivadas del artículo $8 \mathrm{CEDH}$ : Poner en marcha un marco legislativo y administrativo dirigido a la prevención efectiva del daño al medio ambiente y la salud humana; garantizar la protección efectiva de los ciudadanos cuyas vidas podrían estar expuestas a los peligros inherentes a la industria en cuestión; realizar las investigaciones y estudios apropiados, con el fin de prevenir y evaluar de antemano las consecuencias de las actividades que puedan causar daños; garantizar el acceso público a los resultados de estos estudios, así como a la información general, para evaluar el peligro al que cada uno se expone y, por fin, asegurar que las personas afectadas sean capaces de acudir a los tribunales contra cualquier decisión, acto u omisión si consideran que sus intereses no se han tenido suficientemente en cuenta en el proceso de toma de decisiones ${ }^{59}$. En esta sentencia se consideró vulnerado el derecho a la vida privada y familiar del artículo 8 CEDH.

58 También en el caso Öneryildiz c. Turquía, de 30 de noviembre de 2004.

59 Parágrafo 88. 
Sobre el derecho a la asistencia sanitaria, puede citarse, en primer lugar, el caso Berktay c. Turquía, de 1 de marzo de 2001, que afirmó, como obiter dictum y sin extraer mayores consecuencias, la obligación positiva del Estado, en virtud del artículo $2 \mathrm{CEDH}$, de «proteger la vida del individuo contra terceros o contra el riesgo de enfermedad».

El derecho a la asistencia sanitaria fue el objeto de la ya citada decisión de inadmisibilidad La Parola y otros c. Italia. Los demandantes alegaban que los Estados parte del Convenio habían asumido la obligación de asegurar a todos los ciudadanos y, en particular, a los menores y personas con discapacidad, los derechos a la vida y a la salud, lo que se traducía en el derecho a una asistencia sanitaria efectiva. El Tribunal admitió la existencia de obligaciones positivas del Estado en virtud del artículo $8 \mathrm{CEDH}$, pero, sin definirlas, consideró que el comportamiento de éste se había ajustado a esas obligaciones, dada la cuantía de los subsidios que recibían los demandantes por su condición de personas con discapacidad.

En el ya citado caso Calvelli y Ciglio c. Italia, los demandantes alegaron vulneración del derecho a la vida por el fallecimiento de su hijo como consecuencia de negligencia médica en el parto, que tuvo lugar en una clínica privada. El Tribunal consideró que, en virtud del artículo $2 \mathrm{CEDH}$, el Estado estaba obligado a tener establecido un marco reglamentario que obligara a los hospitales, tanto públicos como privados, a la adopción de medidas adecuadas para asegurar la protección de la vida de sus enfermos y también un sistema judicial que permitiera la investigación de los casos de defunciones de personas que se encontraran bajo la responsabilidad de profesionales de la sanidad. En este caso, no se estableció finalmente la vulneración del derecho a la vida, porque los demandantes habían llegado a un acuerdo con los responsables de la clínica, pero el Tribunal afirmó claramente que el artículo $2 \mathrm{CEDH}$ incluía determinadas obligaciones positivas del Estado tendentes a proteger la salud de las personas bajo su jurisdicción, lo que puede verse como un reconocimiento implícito del derecho a la protección de la salud.

De forma más clara, el TEDH estableció una serie de obligaciones positivas del Estado derivadas del artículo $2 \mathrm{CEDH}$ en el caso Oyal c. Turquía, de 23 de marzo de 2010, en el que se había producido un contagio de VIH a través de una transfusión sanguínea en el momento del nacimiento del demandante. Las obligaciones definidas consistían en varios deberes del Estado: impedir la transmisión del VIH a través de las transfusiones, prestar asistencia sanitaria total y gratuita a los infectados por este medio, ofrecer un tratamiento apropiado e investigar las negligencias médicas en relación con el contagio de VIH. En este caso, en que el Tribunal estimó producida una vulneración del artículo 2 CEDH, 
se tuvo en cuenta la responsabilidad indirecta del Estado en el momento de producción del daño ${ }^{60}$.

En la Decisión de Inadmisión Nitecki c. Polonia, de 21 de marzo de 2001, el demandante alegaba vulneración del artículo $2 \mathrm{CEDH}$ por la negativa del Estado de reembolsarle el coste íntegro de un medicamento que era imprescindible para mantener su vida. Aunque no se admitió a trámite la demanda porque el Estado había abonado el 70 por ciento del coste del medicamento, lo cual se consideró adecuado por el Tribunal en este caso, se afirmó expresamente que:

«En lo que respecta al alcance de las obligaciones positivas del Estado en materia de prestación de servicios de salud, el Tribunal ha señalado que la cuestión puede plantearse bajo el ámbito de aplicación del artículo 2 cuando se demuestre que las autoridades de un Estado parte ponen en peligro la vida de un individuo mediante la negación de la asistencia sanitaria que se han comprometido a poner a disposición de la población en general.»

En el caso Roche c. Reino Unido, de 19 de octubre de 2005, el demandante sufría diversos problemas de salud que él consideraba consecuencia de su participación en varias pruebas con gas mostaza y gas nervioso realizadas bajo los auspicios de las Fuerzas Armadas Británicas. El Tribunal recordó los requisitos para considerar que existe una obligación positiva del Estado: «Para saber si existe tal obligación, es preciso tener en cuenta el justo equilibrio entre el interés general y los intereses contrapuestos del individuo en cuestión» ${ }^{61}$. Aunque el Tribunal desvinculó algunos de los padecimientos del demandante de las pruebas realizadas, estimó que la falta de información sobre las consecuencias de tales pruebas causó al demandante una gran incertidumbre y fue causa de sus problemas de estrés y ansiedad. Por ello, consideró vulnerado el derecho a la vida privada y familiar del artículo $8 \mathrm{CEDH}$.

Los casos en los que sí se ha establecido claramente una obligación positiva del Estado de prestar asistencia sanitaria completa son los relativos a las personas que se encuentran bajo la custodia del Estado, esto es, las personas detenidas y la población reclusa. Así se ha afirmado, aun sin mencionar expresamente el término obligación positiva, en los casos Ananyev y otros c. Rusia, ya citado, y Iacov Stanciu c. Rumanía, de 24 de julio de 2012, entre otros. Sí habla de obligaciones positivas la sentencia piloto Torreggiani c. Italia, de 8 de enero de 2013, en la que se afirma que el Estado tiene la obligación positiva de asegurarse de que una persona detenida esté en condiciones que sean compatibles con el respeto a la dignidad huma-

60 Binder, C. y Schobesberger, T. (2015), El Tribunal Europeo de Derechos Humanos y los derechos sociales..., cit., p. 111.

61 Parágrafo 157. 
na, que no se le someta a angustia o dificultad que exceda el nivel inevitable de sufrimiento inherente a la detención y que, dadas las exigencias prácticas del encarcelamiento, su salud y bienestar estén asegurados adecuadamente ${ }^{62}$.

\subsection{El derecho a la vivienda}

Con relación al derecho a la vivienda, existen varias sentencias y decisiones de las que se puede deducir que el Tribunal no reconoce un derecho subjetivo a obtener una vivienda ni una obligación del Estado de garantizar una vivienda a las personas bajo su jurisdicción, según hemos visto. Sin embargo, en varios pronunciamientos, se establecen diferentes tipos de obligaciones positivas con relación a la vivienda en las que se muestra que el Tribunal no es indiferente a este derecho reconocido en el artículo 31 de la Carta Social Europea revisada.

En la mencionada decisión Marzari c. Italia, el demandante era una persona con discapacidad que había dejado de pagar el alquiler del apartamento donde vivía porque éste no se adaptaba a sus especiales necesidades y hasta tanto se llevaran a cabo las reformas necesarias. Como consecuencia de ello, fue desalojado de esta vivienda. La demanda fue inadmitida porque el Tribunal entendió que las autoridades locales habían cumplido sus obligaciones positivas con relación al artículo $8 \mathrm{CEDH}$ (pusieron a disposición del demandante otro apartamento) pero, aunque no concretó en qué consistían tales obligaciones, realizó unas afirmaciones interesantes:

«El Tribunal considera que, si bien el artículo 8 no garantiza la resolución por parte del Estado de los problemas relacionados con la vivienda, el que el Estado rehúse la asistencia a una persona con una discapacidad grave puede incluirse en el ámbito de aplicación del artículo 8 debido al impacto negativo de esta decisión en la vida privada de la persona.»

En la decisión de inadmisión Codona c. Reino Unido, de 7 de febrero de 2006, el Tribunal especificó más en qué consistiría la obligación positiva del Estado derivada del artículo $8 \mathrm{CEDH}$ con relación al acceso a la vivienda de una familia gitana: El Estado debía facilitar su modo de vida nómada aunque solo en el caso de que existiese un espacio adecuado para ello, lo que no se daba en este caso.

Por el contrario, en el caso Moldovan y otros c. Rumanía, de 12 de julio de 2005, el Tribunal apreció vulneración de los artículos 3 y 8 CEDH por incumplimiento de las obligaciones positivas del Estado. En este caso, en el que agentes privados con la participación de agentes estatales habían demolido las viviendas

62 Parágrafo 65. 
de los recurrentes, la sentencia estableció que el Estado había incumplido sus obligaciones positivas de respeto y protección de la vida privada y familiar de las personas bajo su jurisdicción, lo que incluye la protección de sus hogares. No queda claro, sin embargo, en qué deben consistir estas obligaciones positivas y, además, otorga un margen de apreciación al Estado que, en este caso, fue excedido.

Algo más clara en la determinación de las concretas obligaciones positivas con respecto a la vivienda, la Sentencia dictada en el citado caso Öneryildiz c. Turquía estableció vulneración del artículo 1 Protocolo $1 \mathrm{CEDH}$ (derecho de propiedad) por la destrucción de la vivienda del recurrente, causada por una explosión de gas metano producida en un vertedero próximo a dicha vivienda (así como vulneración del artículo $2 \mathrm{CEDH}$ — derecho a la vida — por la muerte de nueve parientes del demandante en dicha explosión). Es interesante destacar que esta vivienda había sido construida ilegalmente, sin la correspondiente autorización oficial. Aun así, las autoridades habían tolerado esta vivienda por varios años, con lo que se había producido un reconocimiento de facto del interés patrimonial del recurrente y su familia en dicha vivienda. La sentencia reconoce vulneración de las obligaciones positivas sustantivas y procedimentales del Estado en relación con el derecho a la vida del artículo $2 \mathrm{CEDH}$, pero también examina la cuestión desde el punto de vista del artículo 1 Protocolo $1 \mathrm{CEDH}$ (derecho de propiedad). Y concluye que el Estado incumplió sus obligaciones positivas de proteger la propiedad del recurrente, que consistían en medidas de protección para impedir la destrucción de su vivienda.

\section{A MODO DE CONCLUSIÓN}

Aunque los derechos sociales de prestación no están expresamente reconocidos en el CEDH (salvo el derecho a la educación del artículo 2 Protocolo 1), el Tribunal Europeo, en su jurisprudencia, ha protegido de alguna forma varios de estos derechos como el derecho a la protección de la salud, a la vivienda, a la protección social o a la protección de las personas con discapacidad. Para ello ha utilizado varias técnicas, en especial, la inclusión de estos derechos sociales prestacionales en el ámbito de protección de alguno de los derechos que sí están protegidos en el Convenio, en especial, el derecho a la vida (art. 2), la prohibición de la tortura y los tratos inhumanos y degradantes (art. 3), el derecho a la vida privada y familiar (art. 8) y el derecho de propiedad del artículo 1 Protocolo 1.

Otra de las técnicas utilizadas ha sido la doctrina de las obligaciones positivas del Estado. Pero el TEDH ha aplicado esta doctrina en mucha mayor medida con relación a los derechos civiles y políticos que con relación a los derechos 
sociales de prestación. No es solo porque estos últimos no están expresamente reconocidos en el Convenio Europeo (con la salvedad indicada), sino también porque el Tribunal ha considerado que las decisiones sobre el gasto que implica la garantía de estos derechos prestacionales es una decisión que, en general, le corresponde adoptar a los Estados y, concretamente, al poder legislativo y al poder ejecutivo estatales. En este punto, el Tribunal de Estrasburgo ha adoptado una postura de autocontención y ha dejado un amplio margen de apreciación a los Estados en la determinación del contenido concreto de las obligaciones derivadas de derechos como la protección de la salud, la vivienda, la protección social o, incluso, el derecho a la educación (caso Lingüístico Belga, de 1968). Así, en la decisión de inadmisibilidad Zehnalova y Zehnal c. República Checa (de 2002) consideró, en una interpretación restrictiva, que las obligaciones positivas derivadas del artículo $8 \mathrm{CEDH}$ en lo referente a la protección de las personas con discapacidad solo podían afirmarse cuando la deficiencia afectaba al núcleo del derecho a la vida privada y familiar, lo que no sucedía en este caso.

Aun así, existen varias sentencias y decisiones en las que el Tribunal impone obligaciones positivas a los Estados derivadas de ciertos derechos sociales de prestación. En algunas de estas resoluciones se habla de ciertas obligaciones positivas del Estado sin definirlas detalladamente (caso Berktay c. Turquía, de 2001, sobre la asistencia sanitaria) y en otras se reconoce la existencia de ciertas obligaciones positivas pero se deniega la protección porque se considera que el Estado ha cumplido adecuadamente con ellas (Nitecki c. Polonia, de 2001, sobre asistencia sanitaria; La Parola y otros c. Italia, de 2000, sobre asistencia sanitaria y protección de las personas con discapacidad o Marzari c. Italia, de 1999, sobre el derecho a la vivienda).

Finalmente, existen algunas sentencias en las que el Tribunal detalla cuáles son esas obligaciones (incluso hay casos en que condena al Estado por incumplirlas). Esto ha sucedido, en primer lugar, cuando se han producido unos daños en los que existe una responsabilidad directa o indirecta del Estado (Tatar c. Rumanía, de 2009, y Oyal c. Turquía, de 2010, sobre protección de la salud y Öneryildiz c. Turquía, de 2004, sobre el derecho a la vivienda). En segundo lugar, también se han afirmado concretamente cuáles son las obligaciones positivas derivadas de derechos sociales de prestación cuando se trata de personas que están bajo la tutela directa del Estado, como los detenidos y los internos en prisiones (Torreggiani c. Italia, de 2013, sobre protección de la salud y el bienestar). Lo mismo se ha hecho en casos relativos a personas especialmente vulnerables, como la minoría gitana (Codona c. Reino Unido, de 2006, sobre el derecho a la vivienda).

Se puede afirmar que la protección de los derechos sociales de prestación ofrecida por la doctrina de las obligaciones positivas del Estado en la jurispru- 
dencia del Tribunal de Estrasburgo es todavía incipiente y poco desarrollada. Pero marca un camino que habrá que seguir explorando en el futuro. Es cierto que son los Estados quienes deben tomar la iniciativa en la protección de estos derechos, pero también es cierto que las instancias internacionales tienen un importante papel que cumplir. Como el mismo Tribunal reconoció en la decisión de inadmisibilidad Zehnalova y Zehnal c. República Checa, la continua evolución de la sociedad europea requiere cada vez mayores esfuerzos de los gobiernos nacionales para hacer frente a los déficits de protección de los derechos sociales. En mi opinión, cuando un Estado incumpla de forma flagrante con el mínimo exigible de protección según los estándares internacionales comúnmente aceptados, los tribunales internacionales y, de forma especial por la vinculatoriedad de sus sentencias, el Tribunal Europeo de Derechos Humanos puede y debe obligarle a adaptar su legislación y sus políticas a esos estándares mínimos.

Title:

Social rights of assistance and positive obligations of the State in the case-law of the European Court of Human Rights.

\section{Summary:}

1. Introduction. 2. The social rights of assistance and its problematic justiciability. 3. The positive obligations of the state in the case law of the ECtHR. 4. The protection techniques of the social rights of assistance in the case law of the ECtHR. 4.1. General approach. 4.2. Application of the prohibition of discrimination of article 14 ECtHR to certain social benefits. 4.3. Extension of the content of several rights recognized in the Convention. 5. In particular: the protection of social rights of assistance through the doctrine of the positive obligations of the state. 5.1. The right to health protection. 5.2. The right to housing. 6. By way of conclusion.

\section{Resumen:}

El Convenio Europeo de Derechos Humanos no reconoce expresamente los derechos sociales de prestación (a excepción del derecho a la educación). A pesar de ello, el Tribunal de Estrasburgo ha realizado una interpretación extensiva de los derechos civiles y políticos reconocidos para incluir, de diversas formas, la protección de aquellos 
derechos. Una de las técnicas utilizadas ha sido la doctrina de las obligaciones positivas del Estado. Aunque el Tribunal ha aplicado esta doctrina, fundamentalmente, a los derechos civiles y políticos, podemos encontrar algunas resoluciones en las que establece determinadas obligaciones positivas estatales para proteger derechos como la protección de la salud, la vivienda, la protección social o la protección de las personas con discapacidad. En general, se trata de reconocimientos generales y poco concretos pero, en algunos casos, ha detallado cuáles son estas obligaciones.

Esto lo ha hecho, en primer lugar, en casos en que se habían producido daños cuya responsabilidad era directa o indirectamente del Estado. En segundo lugar, cuando se trataba de personas que se encontraban bajo la tutela del Estado, como las personas detenidas o internas en prisiones. $Y$, en tercer lugar, cuando los afectados eran personas especialmente vulnerables (discapacitados o pertenecientes a la minoría gitana). Aunque se trata de una interpretación incipiente y poco desarrollada, muestra un camino en el que se debería profundizar en el futuro. Es generalmente admitido que son los Estados quienes deben tener la iniciativa en el diseño y establecimiento de los derechos sociales de prestación pero, en caso de conductas y omisiones estatales manifiestamente contrarias a los estándares internacionales, el Tribunal Europeo debería obligar a los Estados mediante sus sentencias a dictar una legislación o establecer políticas que hagan efectivos estos derechos.

El artículo consta de una introducción, cuatro epígrafes de contenido y una conclusión final. En el segundo epígrafe se aborda la cuestión de la problemática justiciabilidad de los derechos sociales de prestación. En el tercero se hace referencia a la doctrina de las obligaciones positivas del Estado en la jurisprudencia del TEDH. En el cuarto se apuntan las principales técnicas que ha utilizado el TEDH para proteger los derechos sociales de prestación y, en particular, la extensión del contenido de algunos derechos civiles y políticos. En el quinto epígrafe se analiza cómo se ha utilizado la técnica de las obligaciones positivas del Estado en la protección de los derechos sociales de prestación y, en concreto, del derecho a la protección de la salud y del derecho a la vivienda.

\begin{abstract}
:
The European Convention on Human Rights does not expressly recognize any social rights of assistance (except the right to education). In spite of this, the Strasbourg Court has made a broad interpretation of recognized civil and political rights to include, in different ways, the protection of those rights. One of the techniques used by the
\end{abstract}


Court has been the doctrine of the State's positive obligations under the ECHR. Although the Court has essentially applied this doctrine to the civil and political rights, we can find some resolutions in which it establishes certain positive state obligations to protect rights such as protection of health, housing, social benefits or protection of people with disabilities. Generally, these are general and not very specific recognitions, but in some cases, they have detailed what these obligations are.

Firstly, this has been done in cases where there was damage which was directly or indirectly the responsibility of the State. Secondly, regarding people who were under the protection of the State, such as persons detained or interned in prisons. And, thirdly, when those affected were particularly vulnerable (disabled or belonging to the Roma minority). Although it is an incipient and underdeveloped interpretation, it shows a way in which should be further deepened. It is generally accepted that it is the States that must take the initiative in designing and establishing social rights of assistance but, in the case of state conduct and omissions that are manifestly contrary to international standards, the European Court should oblige States with their judgements to enact legislation or develop policies to give effect to these rights.

The article consists of an introduction, four content epigraphs and a final conclusion. The second section deals with the question of the problematic justiciability of social rights of assistance. The third refers to the doctrine of the positive obligations of the State in the Case Law of the ECtHR. The fourth section outlines the main techniques used by the ECtHR to protect the social rights of assistance and, in particular, expanding the scope of some civil and political rights. The fifth section analyzes the use of the technique of positive obligations of the State in the protection of social rights of assistance and, in particular, the right to protection of health and the right to housing.

\section{Palabras clave:}

Derechos sociales, derechos sociales de prestación, obligaciones positivas del Estado, Tribunal Europeo de Derechos Humanos.

Key words:

Social rights, social rights of assistance, positive obligations of the State, European Court of Human Rights. 